Tropical Journal of Pharmaceutical Research September 2019; 18 (9): 1961-1967

ISSN: 1596-5996 (print); 1596-9827 (electronic)

(1) Pharmacotherapy Group, Faculty of Pharmacy, University of Benin, Benin City, 300001 Nigeria.

\title{
Comparative evaluation of the chemotherapeutic efficacies of two salts of diminazene aceturate in Trypanosoma brucei brucei infected dogs
}

\author{
Ukamaka U Eze ${ }^{1}$, Ifeanyi G Eke ${ }^{2 \star}$, Ikenna O Ezeh ${ }^{3}$, Terry A Nzeakor ${ }^{3}$, Callistus \\ Owube $^{2}$, Ann Dede ${ }^{1}$, Boniface M Anene ${ }^{1}$ \\ ${ }^{1}$ Department of Veterinary Medicine, ${ }^{2}$ Department of Physiology and Pharmacology, ${ }^{3}$ Department of Veterinary Parasitology \\ and Entomology, Faculty of Veterinary Medicine, University of Nigeria, Nsukka, Nigeria
}

*For correspondence: Email: ifeanyi.eke@unn.edu.ng; Tel: +234-8037494699

Sent for review: 20 March 2019

Revised accepted: 22 August 2019

\begin{abstract}
Purpose: To compare the anti-trypanosomal efficacies of 4,4-(diazoaminedibenzamidinetrihydrate) diacetate (4,4-DDBT) and 4,4-(diazoamino) benzamidine $(4,4-D B)$ in experimental canine trypanosomosis.

Methods: The efficacies of 4,4-DDBT and 4,4-DB were evaluated in 4 groups of dogs $(n=3)$ designated A-D. Group A was normal control without infection or drug treatment, group $B$ did not receive any drug treatment but was infected with Trypanosoma brucei brucei, while groups $C$ and $D$ were infected with $T$. b. brucei and treated with 4,4-DDBT $(3.5 \mathrm{mg} / \mathrm{kg})$ and 4,4-DB $(3.5 \mathrm{mg} / \mathrm{kg})$, respectively.

Results: The incubation period of the infection was 6 - 9 days post-infection. Treatment of the dogs with 4,4-DDBT led to zero parasitaemia $48 \mathrm{~h}$ post-treatment, while there was only a decrease in parasitemia to $\log 6$ in 4,4-DB-treated dogs. Resurgence of parasite into the blood stream occurred in 4,4-DDBTtreated dogs 6 days after initial parasite clearance. Blood analyses post-treatment revealed elevated leucocytes and lymphocytes in 4,4-DB-treated dogs $(p<0.05)$. Packed cell volume was also observed to be higher in 4,4-DDBT-treated group when compared to 4,4-DB group $(p<0.05)$.

Conclusion: These findings suggest that 4,4-DDBT is more efficacious in the clinical management of canine trypanosomosis caused by T. b. brucei. However, it does not prevent relapse of infection. Based on these findings, therefore, 4,4-DDBT should be the diminazene salt of choice when indicated in the clinical management of T. b. brucei infection in dogs.
\end{abstract}

Keyword: Dogs, Trypanosomes, 4,4-(Diazoamino) benzamidine, 4,4-(diazoaminedibenzamidinetrihydrate) diacetate

This is an Open Access article that uses a fund-ing model which does not charge readers or their institutions for access and distributed under the terms of the Creative Commons Attribution License (http://creativecommons.org/licenses/by/4.0) and the Budapest Open Access Initiative (http://www.budapestopenaccessinitiative.org/read), which permit unrestricted use, distribution, and reproduction in any medium, provided the original work is properly credited.

Tropical Journal of Pharmaceutical Research is indexed by Science Citation Index (SciSearch), Scopus, International Pharmaceutical Abstract, Chemical Abstracts, Embase, Index Copernicus, EBSCO, African Index Medicus, JournalSeek, Journal Citation Reports/Science Edition, Directory of Open Access Journals (DOAJ), African Journal Online, Bioline International, Open-J-Gate and Pharmacy Abstracts

\section{INTRODUCTION}

Trypanosomes are one of the endemic heamoprotozoan parasites that cause severe mortality in domestic dogs in Nigeria. This is due to the ubiquitous nature of Glossina spps in the country [1,2]. Human and animal African trypanomosis are usually fatal without 
chemotherapy [3]. In veterinary medicine, diminazeneaceturate (DA) and isomethamidium chloride are the trypanocides commonly employed for curative and prophylactic regimens respectively [4]. DA is the most common and available trypanocide used in the treatment of trypanosomosis in dogs. Unfortunately, the drug is outmoded and no new drug has been produced against the organism [5]. It has been reported that the recommended dose of DA; 3.5 - $7 \mathrm{mg} / \mathrm{kg}$ for canine trypanosomosis caused by Trypanosoma $b$. brucei does not clear the parasite from the animal's system [6] and this has been linked to resistance by trypanososmes [7].

The total dependence on drug in the treatment of trypanosomosis has led to the emergence of resistant trypanosomes [8]. Rapid development of resistance by trypanosomes to DA has been reported in different species of animal $[1,9,10]$. This problem of resistance is of high public health importance, because dogs live in close proximity to humans, and, therefore, can easily transmit the resistant trypanosomes to man [11]. Resistance to trypanocide is usually manifested as relapse of infection. Variability in the quality of DA in the market has been reported with majority of the brands containing less than the active compound (DA) as indicated on the label [1]. Substandard preparations at lower price have led to the development of therapeutic failure and possible emergence of DA resistant trypanosomes [12]. However, apart from drug quality, other factors such as under-dosing and rapid re-exposure after treatment with therapeutic agents with short duration of action may also lead to development of resistance [9].

In Nigeria, trypanosomosis is one of the commonest endemic diseases severely affecting domestic dogs. The issue of relapse of infection is now commonplace and has resulted in the infected dogs being treated severally with the same drug because there is limited range of trypanocides. This study compared the efficacies of two salts of DA; 4,4-DDBT and 4,4$\mathrm{DB}$ in the chemotherapy of canine trypanosomosis caused by Trypanosoma $b$. brucei, with a view of achieving complete cure without relapse infection.

\section{EXPERIMENTAL}

\section{Animals}

Twelve (12) clinically healthy male dogs between the ages of 6 to 12 months were used. The dogs were housed in the Department of Veterinary Medicine, University of Nigeria, Nsukka, Nigeria dog kennel protected from flies. The dogs were fed with pelletized dried dog food twice daily and water was provided ad libtum. The dogs were allowed 3 weeks for acclimatization. The dogs were dewormed using Prasizam ${ }^{\circledR}$ (combination of Febentel, Pyrantelpalmoate and praziquantel). They were vaccinated against rabies and then DHLPP (distemper, parvoviral enteritis, parainfluenza, canine hepatis and leptospirosis polyvalent vaccine). They were then screened for blood parasites before the commencement of the experiment. The protocol for the experiment is in compliance with National Institute of Health (NIH) guidelines [13] and received approval from the Experimental Animal Ethics Committee of the Faculty of Veterinary Medicine, University of Nigeria, Nsukka (approval no: UNFVM/08/18/7).

\section{Trypanosome parasite}

Trypanosoma brucei brucei used was the federe strain obtained from the Department of Veterinary Parasitology and Entomology, University of Nigeria, Nsukka. The dogs were infected with 1 million trypanosomes suspended in $1 \mathrm{ml}$ of phosphate buffered saline (PBS).

\section{Drugs}

The brand containing $4,4-\mathrm{DB}$ is a commonly used trypanocide which costs about \$0.69per sachet. Each sachet contained $2.36 \mathrm{~g}$ and administered as a $7 \%$ solution $(3.5 \mathrm{mg} / \mathrm{kg})$ intramuscularly stat. The brand containing 4,4DDBT is a new trypanocide recently introduced into the Nigerian market. It is sold at $\$ 8.33$ per vial. Each vial contains $1.0 \mathrm{~g}$ powder which is administered as a $5 \%$ solution $(3.5 \mathrm{mg} / \mathrm{kg})$ intramuscularly stat.

\section{Experimental design}

The dogs were assigned to 4 groups (A-D) $(n=$ 3). Group A (uninfected untreated), each dog in groups B-D was infected with 1 million trypanosomes intraperitoneum. After infection, group $B$ was left untreated, group $C$ and $D$ dogs were each treated with 4,4-DDBT and 4,4-DB respectively following onset of parasitemia 10 days post-infection. Parameters such as survivability/clinical signs, PCV, hemoglobin concentration $(\mathrm{Hb})$, parasitaemia, temperature, heart rate, weight, erythrocyte count, total and differential leucocyte count were used to evaluate the efficacy of the drugs. The clinical signs, parasitaemia, heart rate and temperature were monitored daily, while PCV, Hb, erythrocyte count and total and differential leucocyte counts were obtained $0,7,14$ and 21 days postinfection. 


\section{Collection of blood samples}

Blood samples were obtained through the cephalic vein using 21 gauge needles. Blood samples for haematology $(1 \mathrm{ml})$ was collected into EDTA sample bottles, while $0.1 \mathrm{ml}$ for evaluation of parasitaemia was collected directly into a microscope slide and covered with cover slip.

Parasitaemia was quantified using standard technique [14]. Hemoglobin concentration, PCV, total and differential leucocyte counts, and erythrocyte counts were determined using standard techniques $[15,16]$.

\section{Data analysis}

Data generated were presented in figures and tables as mean with standard errors of means. Analysis of variance was used to analyze the data. Duncan multiple range tests were used to separate variant means, and $p<0.05$ ) was considered significant.

\section{RESULTS}

\section{Clinical signs and parasitological finding}

The incubation period observed in this study was 6 - 9 days post infection. Clinical signs such as anorexia, pale mucous membrane, depression, reluctance to move and pyrexia were observed in the infected dogs. These observed clinical signs disappeared following treatment in the treated groups after parasitaemia disappeared in group treated with 4,4-DDBT (group C) or declined in those treated with 4,4-DB (group D). The clinical signs gradually returned 6 days post-treatment when the infection relapsed. However, in the infected untreated group (group B), the signs gradually developed into more serious signs such as severe emaciation, ocular and nasal discharges, edema, enlarged abdomen and death.

Parasites cleared from the blood of dogs treated with 4,4-DDBT $48 \mathrm{~h}$ post-treatment and the dogs remained aparasitaemic until day 6 posttreatment when relapse occurred and parasitaemia gradually returned. There was a decline but not total clearance of parasitaemia (log 6.9) in dogs in group D and level of parasitaemia continued to fluctuate until the experiment was terminated on day 21. Parasitaemia was high, fluctuating and very evident in infected untreated dogs and eventually led to their death between days 17 - 19 postinfection (Figure 1).

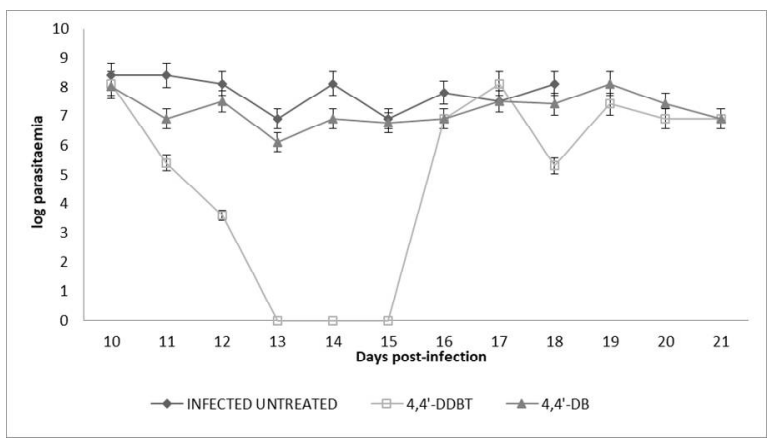

Figure 1: Effect of 4,4-DDBT and 4,4-DB on parasitaemia in T. b. brucei infected dogs

Effect of 4,4-DDBT and 4,4-DB on rectal temperature in $T$. b. brucei infected dogs

Twenty-four hours post-treatment, rectal temperatures of dogs in groups $C$ and $D$ declined significantly $(p<0.05)$ in relation to dogs in group $B$ and this was maintained until day 16 postinfection when relapse occurred. However, dogs treated with 4,4-DB had lower temperatures when compared with dogs treated with 4,4-DDBT (Figure 2).

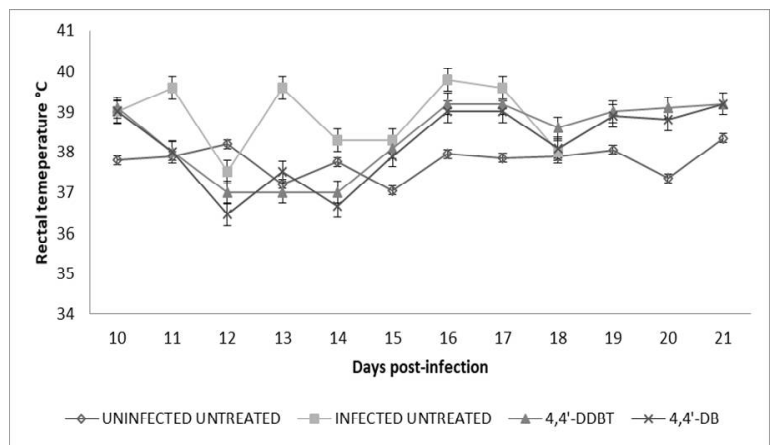

Figure 2: Effect of 4,4'-DDBT and 4,4'-DB on rectal temperature of $T$. b. brucei infected dogs

Effect of 4,4'-DDBT and 4,4'-DB on Heart rate of dogs in experimental Trypanosoma. $b$. brucei infection

Heart rate of dogs in group B was significantly ( $p$ $<0.05$ ) increased from day 12 to 14 postinfection. However, lower heart rate $(p<0.05)$ was recorded in dogs in group $C 11$ days postinfection compared to those in groups $B$ and $D$ (Figure 3).

\section{Hematological findings}

Red blood cell counts, PCV and hemoglobin (Hb) concentration

Following infection, the RBC number, PCV and 


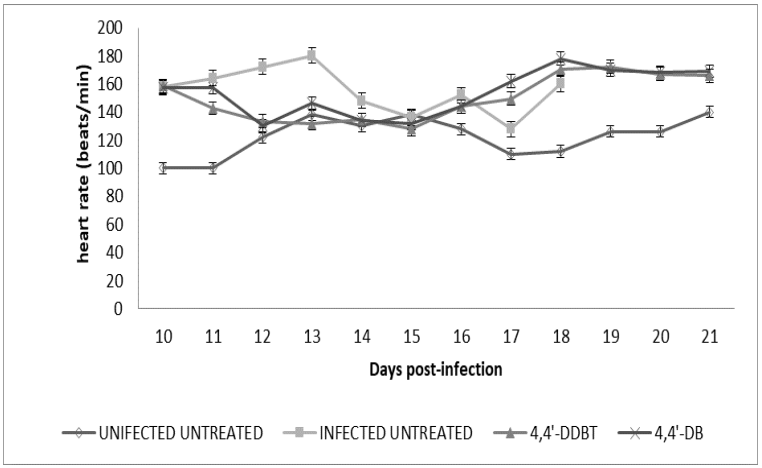

Figure 3: Effect of 4,4-DDBT and 4,4-DB on the heart rate of dogs in experimental Trypanosoma b. brucei infection

$\mathrm{Hb}$ concentration declined $(\mathrm{p}<0.05)$ in all the infected dogs on day 7 post-infection.

Nevertheless following institution of treatment, there was an increase $(p<0.05)$ in the level of these erythrocytic indices in groups $C$ and $D$ dogs on day 14, though the levels of RBC in groups $C$ and $D$ were still lower $(p<0.05)$ than those of dogs in group A on day 21. Meanwhile, the PCV of dogs in group $C$ was higher $(p<$ 0.05 ) than those of group $D$ on day 21 ; however, there was no difference $(p>0.05)$ in their RBC number and $\mathrm{Hb}$ concentrations (Table 1 ).

\section{White blood cells}

By day 7 post-infection, the total WBC count of all the infected dogs had significantly decreased in relation to those of dogs in group A. Although, treatment with either 4,4-DDBT or 4,4-DB lead to significant increase of the WBC of the treated dog, those of the untreated remained low on day 14 post-infection. Nevertheless, by day 21, the total WBC of dogs treated with 4,4-DB was significantly higher than those of groups $A$ and $C$ (Table 2).

\section{Differential white blood cell count}

Infection of dogs with Trypanosoma $b$. brucei lead to increase $(p<0.05)$ in the lymphocyte

Table 1: Effect of treatment with either 4,4-DDBT or 4,4-DB on the RBC, PCV and Hb concentration of dogs infected with Trypanosoma b. brucei

\begin{tabular}{|c|c|c|c|c|}
\hline \multirow[t]{2}{*}{ Parameter } & \multicolumn{4}{|c|}{ Days post-infection } \\
\hline & 0 & 7 & 14 & 21 \\
\hline \multicolumn{5}{|l|}{$\operatorname{RBC}\left(\times 10^{6} / \mu \mathrm{L}\right)$} \\
\hline A & $4.6 \pm 10.4$ & $4.8 \pm 13.6^{a}$ & $4.8 \pm 80.0^{a}$ & $4.8 \pm 13.9^{a}$ \\
\hline B & $4.8 \pm^{34} .1$ & $3.0 \pm 30.0^{\mathrm{b}}$ & $2.6 \pm 22.6^{\mathrm{b}}$ & NA \\
\hline C & $4.6 \pm 24.9$ & $3.1 \pm 37.2^{b}$ & $4.1 \pm 17.7^{\mathrm{a}}$ & $3.6 \pm 90.2^{c}$ \\
\hline D & $4.7 \pm 63.7$ & $3.2 \pm 62.6^{\mathrm{b}}$ & $3.9 \pm 14.0^{\mathrm{a}}$ & $3.3 \pm 53.9^{c}$ \\
\hline \multicolumn{5}{|l|}{ PCV (\%) } \\
\hline A & $41.5 \pm 0.50$ & $41.0 \pm 0.6^{a}$ & $42.5 \pm 6.5^{a}$ & $42.5 \pm 0.3^{a}$ \\
\hline B & $40.6 \pm 6.76$ & $34.5 \pm 0.5^{b}$ & $20.0 \pm 0.2^{b}$ & NA \\
\hline C & $41.0 \pm 0.57$ & $33.0 \pm 1.2^{b}$ & $30.3 \pm 1.5^{c}$ & $28.6 \pm 1.5^{\mathrm{c}}$ \\
\hline D & $40.6 \pm 4.05$ & $34.6 \pm 2.2^{b}$ & $28.5 \pm 3.5^{c}$ & $18.3 \pm 2.3^{d}$ \\
\hline \multicolumn{5}{|l|}{ Hb conc. (g/dL) } \\
\hline A & $13.2 \pm 2.6$ & $13.5 \pm 3.3^{\mathrm{a}}$ & $13.7 \pm 2.7^{\mathrm{a}}$ & $13.9 \pm 1.5^{\mathrm{a}}$ \\
\hline B & $13.1 \pm 0.5$ & $9.5 \pm 1.3^{b}$ & $6.9 \pm 0.3^{b}$ & NA \\
\hline $\mathrm{C}$ & $13.2 \pm 0.6$ & $9.0 \pm 1.7^{b}$ & $11.0 \pm 0.2^{\mathrm{a}}$ & $9.2 \pm 0.3^{c}$ \\
\hline $\mathrm{D}$ & $13.3 \pm 0.2$ & $9.6 \pm 2.7^{\mathrm{D}}$ & $10.6 \pm 1.0^{a}$ & $8.1 \pm 0.2^{c}$ \\
\hline
\end{tabular}

Table 2: Total WBC $\left(\times 10^{3} / \mu \mathrm{L}\right)$ count of dogs infected with T. b. brucei and treated with either 4,4-DDBT or 4,4DB

\begin{tabular}{ccccc}
\hline \multicolumn{5}{c}{ Days post-infection } \\
\hline A & $\mathbf{0}$ & $\mathbf{7}$ & $\mathbf{1 4}$ & $\mathbf{2 1}$ \\
B & $18.2 \pm 0.6$ & $18.2 \pm 2.4^{\mathrm{a}}$ & $18.2 \pm 2.5^{\mathrm{a}}$ & $18.1 \pm 0.7^{\mathrm{a}}$ \\
C & $17.9 \pm 3.2$ & $15.9 \pm 2.2^{\mathrm{b}}$ & $12.0 \pm 0.2^{\mathrm{C}}$ & $\mathrm{NA}$ \\
D & $18.6 \pm 4.3$ & $16.8 \pm 4.5^{\mathrm{b}}$ & $21.7 \pm 7.6^{\mathrm{b}}$ & $21.9^{\mathrm{b}} \pm 0.3^{\mathrm{C}}$ \\
\hline
\end{tabular}

\footnotetext{
${ }^{a, b, c} p<0.05 ;$. .NA: not available because the dogs died. A: uninfected untreated, B: infected untreated, C: 4,4-
} DDBT $(3.5 \mathrm{mg} / \mathrm{kg})$, D: $4,4-\mathrm{DB}(3.5 \mathrm{mg} / \mathrm{kg})$ 
Table 3: Lymphocyte and neutrophil counts of $T$. b. brucei infected dogs treated with 4,4-DDBT and 4,4-DB

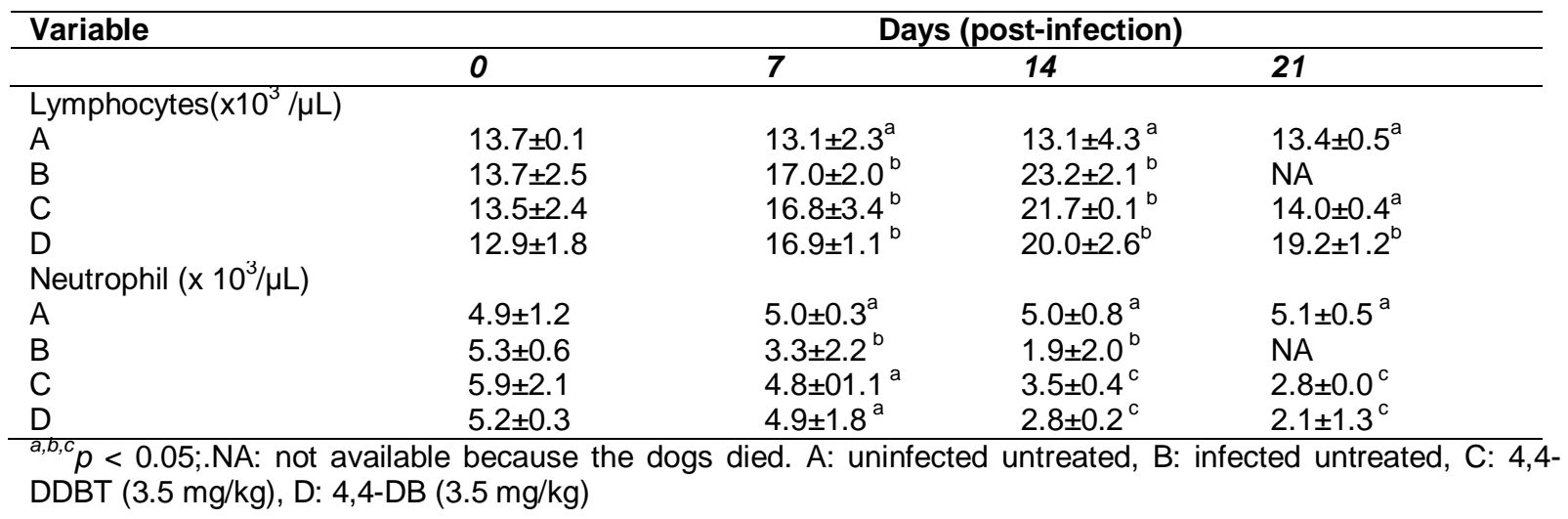

Table 4: Body weights $(\mathrm{kg})$ of dogs infected with T. b. brucei and treated with 4,4-DDBT or 4,4-DB

\begin{tabular}{ccccc}
\hline \multicolumn{5}{c}{ Days (post-infection) } \\
\hline A & $\mathbf{0}$ & $\mathbf{7}$ & $\mathbf{1 4}$ & $\mathbf{2 1}$ \\
B & $5.7 \pm 0.3$ & $5.9 \pm 0.3^{\mathrm{a}}$ & $6.3 \pm 0.3^{\mathrm{a}}$ & $6.2 \pm 0.8^{\mathrm{a}}$ \\
C & $5.8 \pm 0.3$ & $4.7 \pm 0.3^{\mathrm{b}}$ & $3.6 \pm 0.0^{\mathrm{C}}$ & $\mathrm{NA}$ \\
D & $5.8 \pm 0.8$ & $4.6 \pm 0.5^{\mathrm{b}}$ & $4.3 \pm 0.3^{\mathrm{b}}$ & $4.1 \pm 0.2^{\mathrm{b}}$ \\
& $5.7 \pm 0.8$ & $4.3 \pm 0.7^{\mathrm{b}}$ & $4.0 \pm 0.8^{\mathrm{b}}$ & $4.2 \pm 0.5^{\mathrm{b}}$ \\
\hline
\end{tabular}

${ }^{a, b} p \mathrm{p}<0.05$;.NA: not available because the dogs died. A: uninfected untreated, B: infected untreated, C: 4,4DDBT (3.5 mg/kg), D: 4,4-DB (3.5 mg/kg)

counts of all the infected dogs from day 7 postinfection as against those of the uninfected dogs. However, by day 21, Lymphocyte counts of the dogs treated with 4,4-DB were significantly higher than those of groups $A$ and $C$ (Table 3 ).

\section{Effect of 4,4-DDBT and 4,4-DB on body weight of dogs experimentally infected with Trypanosoma brucei brucei}

There was a significant $(p<0.05)$ decrease in the mean body weight of dogs in group $B$ compared to groups $A, C$ and $D$ dogs on day 14 . There was no significant difference in weight between Dogs in groups $C$ and $D$, but dogs in group $A$ had significantly higher body weight than those in groups $C$ and $D$ on days 14 and 21 .

\section{DISCUSSION}

In this study, 4,4-DDBT showed a better therapeutic effect than 4,4-DB in the clinical management of $T$. b. brucei infection at the dose of $3.5 \mathrm{mg} / \mathrm{kg}$ in dogs. However, 4,4-DDBT could not prevent relapse of the infection in the treated dogs indicating resistance of the trypanosomes to the drug.

The establishment of parasitaemia in this study was observed between day 6-9 post-infection, which continued to fluctuate especially in infected untreated group. This fluctuating pattern has been reported by several authors as one of the characteristics of trypanosomosis $[1,17]$. This is as a result of the ability of the trypanosomes to continuously change its surface antigen. This observation agrees with other works done on $T$. b. brucei infection in animals [18]. There was a total clearance of parasitaemia in group treated with 4,4-DDBT within $48 \mathrm{~h}$ post-treatment. However, 4,4-DB could not clear the parasitemia, rather, it caused a decrease to log 6.9. This finding is consistent with the reports of previous researchers who observed that DA does not clear trypanosomes from the animal's system [6].

The efficacy of 4,4-DDBT is, therefore, superior to that of 4,4-DB. Relapse of infection occurred in the 4,4-DDBT treated dogs, indicating that $T . b$. brucei is resistant to this salt of DA. There have been reports on the relapse of infection by $T . b$. brucei after treatment with DA [1, 7, 18]. Reports of relapse of $T$. b. brucei infection have been attributed to the presence of $T . b$. brucei in druginaccessible sites such as the brain; and this often occurs when there is a prolonged period between infection and treatment [18] such that the parasite migrates to brain and after treatment recede from the brain to the blood stream [19].

However, in the present study, the treatment was started on day 10; a day after parasitaemia was established, suggesting that the parasites may not have invaded the brain as treatment was started immediately. Therefore, the relapse may 
not be as a result of the parasites resurfacing into the blood stream from the brain but may be attributed to other factors such as mutation, amplification or deletion, altered drug uptake, drug metabolism, drug-target interaction or efflux [3].

The undulating pyrexia observed in the infected groups could have been responsible for the observed anaemia because erythrocytes were exposed to temperatures higher than normal body temperature which led to increased RBC destruction [20]. High body temperature can equally lead to increased rate of immunochemical reactions with subsequent increase in lipid peroxidation of RBCs.[20].

The 4,4-DB was better at controlling the observed high temperature when compared to 4,4-DDBT because of its antipyrine content. The increased heart rate observed in the infected groups was better controlled by $4,4-D D B T$ than 4,4-DB. This could be because 4,4'-DDBT was better at ameliorating anaemia than 4,4-DB and this could be related to the more efficient control of parasitaemia by $4,4-D D B T$.

Increased heart rate during anaemia is mainly due to compensatory mechanisms of the heart to tissue hypoperfusion [21]. Anaemia observed in this study has been reported by many authors as a constant finding in trypanosomosis [1]. In this study, anaemia was observed in all the infected groups as evidenced by decreases in PCV, $\mathrm{Hb}$ concentration and RBC count by day 7 postinfection. However, these haematological parameters were higher in the group treated with 4,4-DDBT than in infected untreated and 4,4-DB treated group. This finding also indicated that $4,4-D D B T$ was more effective than $4,4-\mathrm{DB}$ in the clinical management of $T$. b. brucei infection in dogs. The anemia in this study could be attributed to the overwhelming hemolytic activities of the trypanosomes [22].

Following infection with $T . b$. brucei, there was elevation of the total white blood cell count of the entire infected groups. Leucocytosis in trypanosomosis is usually as a result of lymphocytosis. This condition is usually an immunological response by the animal to trypanosome infection [22]. A decline in neutrophil count was observed in this study following infection with trypanosomes. This observation agrees with the findings of Allam et al, [23] and this may be as a result of overwhelming immunosuppression in the infected groups.
In this study, the clinical signs such as pale mucus membranes, rough hair coats, emaciation, depression, ocular and nasal discharges, edema, dullness and anorexia were observed. These observations were in agreement with the reports of Ezeokonkwo and Agu, who reported similar clinical signs in $T$. $b$. brucei infected rabbits [24]. These signs gradually disappeared after treatment in the treated groups. However, the disappearance of these signs were faster in dogs treated with 4,4DDBT than in dogs treated with 4,4-DB. The decrease in body weight observed in the infected dogs may have direct relationship with anorexia experienced by the dogs during infection.

\section{CONCLUSION}

The findings show that 4,4-DDBT has greater efficacy than 4,4-DB in the clinical management of $T$. b. brucei infection in dogs. However, the effect of 4,4-DDBT was short-lived as there was relapse of infection in the treated dogs, indicating drug resistance. Therefore, further search for alternative trypanocide (other than DA) should be encouraged to curb the increasing resistance.

\section{DECLARATIONS}

\section{Conflict of interest}

No conflict of interest is associated with this work.

\section{Contribution of authors}

We declare that this work was done by the authors named in this article and all liabilities pertaining to claims relating to the content of this article will be borne by the authors.

\section{Open Access}

This is an Open Access article that uses a funding model which does not charge readers or their institutions for access and distributed under the terms of the Creative Commons Attribution License (http://creativecommons.org/licenses/by/ 4.0) and the Budapest Open Access Initiative (http://www.budapestopenaccessinitiative.org/rea d), which permit unrestricted use, distribution, and reproduction in any medium, provided the original work is properly credited.

\section{REFERENCES}

1. Anene BM, Ezeokonkwo RC, Mmesirionye TI, Tettey JN, Brock JM, Barrett MP, De Koning HP. A diminazene- 
resistant strain of Trypanosoma brucei brucei isolated from a dog is cross-resistant to pentamidine in experimentally infected albino rats. Parasitol 2006; 132: $127-133$

2. Ahmed SK, Rahman AH, Hassan MA, Salih SE, Paone $M$, Cecchi G. An atlas of tsetse and bovine trypanosomosis in Sudan. Parasit Vectors 2016; 9: 194.

3. Baker N, De Koning HP, Mäser P, Horn D. Drug resistance in African trypanosomiasis: the melarsoprol and pentamidine story. Trends parasitol 2013; 29(3): 110-118.

4. Chigozie US, Maduka AB, Ifeanyi JG. Trypanocidal efficacy of diminazene in diabetic rats. Iraqi $J$ Vet Sci 2012; 26: 33-38.

5. Giordani F, Morrison LJ, Rwan TG, De Koning HP, Barrett MP. The animal trypanosomiasis and their chemotherapy: a review. Parasitol 2016; 143: 18621889.

6. Desquesnes M, Gutiérrez C. Animal trypanosomosis: An important constraint for livestock in tropical and subtropical regions. In: Javed MT. Livestock: Rearing, Farming Practices and Diseases, New York, NY: Nova Publishers, New York 2011; 127-144.

7. Gutiérrez C, González-Martín M, Corbera JA, TejedorJunco MT. Chemotherapeutic agents against pathogenic animal Trypanosomes. Microbial pathogens and strategies for combating them: science, technology and education. (Méndez-Vilas A, ed). Spain: Formatex Research Center 2013; 1564-1573.

8. Mungube EO, Vitouley HS, Allegye-Cudjoe E, Diall O, Boucoum Z, Diarra B, Sanogo Y, Randolph T, Bauer B, Zessin $K$ Clausen P. Detection of multiple drugresistant Trypanosoma congolense populations in village cattle of south-east Mali Parasit Vectors 2012; 5 . 155.

9. Geerts S, Homles PH, Diall O, Eisler MC. Africa bovine trypanosomosis: the problem of drug resistance. Trends Parasitol 2001; 17: 25-28

10. Barrett MP, Vincent IM, Burchmore RJ, Kazibwe AJ, Matovu E. Drug resistance in human African trypanosomiasis. Future Microbiol 2011; 6: 1037-1047.

11. Doyle RL. Eficácia de três medicamentos no controle da infecção experimental por Trypanosoma evansi em ratos (Rattus norvegicus) linhagem Wistar. [Master's Thesis]. Santa Maria: Centro de Ciências Rurais da Universidade Federal de Santa Maria; 2006; $p 40$.
12. Barrett MP, Croft SL. Management of trypanosomiasis and leishmaniasis. Bri med bull 2012; 104: 175-196.

13. National Institute of Health $(\mathrm{NIH})$. Guide for the Care and Use of Laboratory Animals. National Academy Press, Washington, DC, USA 1996.

14. Herbert WJ, Lumsden WH. Trypanosoma brucei: A Rapid "Matching" method for estimating the host's parasitaemia. Exp Parasitol 1976; 40; 427-431.

15. Dacie JV, Lewis SM. Practical Haematology, 7th edition, ELSB with Churchill Livingstone, England 1991; 37-85.

16. Baker FJ, Siverston RE, Pallister CJ. Determination of red blood cell indices. In: Baker and Silverston, eds. Introduction to Medical Laboratory Technology. 7th Ed. Felele Rab, Ibadan, Nigeria: Sam-Adex Printers 2000.

17. Mbaya A, Kumshe H, Nwosu CO. The Mechanisms of Anaemia in Trypanosomosis: A Review, Anemia, Dr. Donald Silverberg (Ed.) 2012; 269- 282.

18. Eke IG, Ezeh IO, Ezeudu TA, Eze UU, Anaga AO, Onyeyili PA. Chemotherapeutic efficacy of secnidazolediminazene aceturate combination therapy in experimental Trypanosoma brucei brucei infection in rats. Afr J Pharm Pharmacol 2017; 11: 349-35.

19. Jennings $F W$, Whitelaw $D D$, Holmes $P H$, Chizyuka HKB, Urquhart GM. The brain as a source of relapsing $T$. brucei infection in mice following chemotherapy. Int $J$ Parasitol 1979; 9: 381-384.

20. Igbokwe 10. Mechanisms of cellular injury in African trypanosomiasis, Vet Bull 1994; 64: 611-620.

21. Tuncer M, Gunes $Y$, Guntekin U, Gumrukcuoglu HA, Eryonucu B, Guler N, Dilek I, Demir C. Heart rate variability in patients with iron deficiency anemia. Arq Bras Cardiol 2009; 92: 368-371.

22. Eze Jl, Ajanwachukwu N, Animoke PC, Onoja SO, Anosa GN and Eze UU. Immune Response, Anaemia and Oxidative Stress in Trypanosoma brucei brucei Infected Rats Fed Vitamin E Supplemented Diet. Anti-Infective Agents 2016; 14: 28-37.

23. Allam LD, Ogwu D, Agbede RIS, Sackey AKB. Hematological and serum biochemical changes in gilts experimentally infected with Trypanosoma brucei. Vet. Arhiv 2011; 81: 597-609.

24. Ezeokonkwo RC, Agu WE. Experimental Infections of Domestic Rabbits (Oryctolagus cuniculus) With Trypanosoma brucei and Trypanosoma congolense: A Comparative Study. Niger J Anim Prod 2004; 31: 100 111. 